\title{
PENGEMBANGAN MODUL LELANG PADA SIAPSIAPNIKAH.COM MENGGUNAKAN METODE EXTREME PROGRAMMING DAN KONSEP CROWDSOURCING
}

\author{
${ }^{1}$ Fitasari Wiharni, ${ }^{2}$ Yuli Adam Prasetyo, ${ }^{3}$ Taufik Nur Adi \\ ${ }^{1,2,3}$ Sistem Informasi, Fakultas Rekayasa Industri, Universitas Telkom \\ ${ }^{1}$ fitasariwiharni@gmail.com, ${ }^{2}$ adam@telkomuniversity.ac.id, ${ }^{3}$ taufik.nur.adi@gmail.com
}

\begin{abstract}
Abstrak-Wedding organizer adalah bisnis yang menyediakan produk atau jasa mengenai upacara pernikahan dan mengatur jalannya upacara. Wedding organizer mulai menggunakan internet sebagai media untuk mengiklankan dan mempromosikan produk dan jasanya. Selain itu, penduduk Indonesia lebih mudah menggunakan internet untuk mendapatkan informasi mengenai wedding organizer. Pada faktanya, harga adalah prioritas tertinggi ketika pelanggan mencari dan memilih wedding organizer. Selain mencari paket yang disediakan oleh wedding organizer, pelanggan seringkali menginginkan produk dan jasa diluar paket dan sesuai dengan anggaran. Dari fakta tersebut, penelitian ini membahas pengembangan modul lelang pada aplikasi website siapsiapnikah.com. Pada pengembangan modul sistem lelang digunakan sebagai solusi untuk mencari harga produk dan jasa pernikahan yang sesuai. Untuk mengimplementasikan sistem lelang pada website dengan baik, digunakan konsep crowdsourcing untuk mendapatkan banyak harga dari banyak wedding organizer berdasarkan kebutuhan pelanggan. Selain itu, peneliti menggunakan Extreme Programming sebagai metode pengembangan software dan Codeigniter sebagai framework. Hasil dari penelitian ini adalah aplikasi website yang memiliki sistem lelang untuk membantu pelanggan dalam mencari wedding organizer dan harga yang sesuai. Pelanggan akan mendapatkan banyak pilihan harga dari banyak wedding organizer berdasarkan kebutuhan pernikahannya.
\end{abstract}

Kata kunci: aplikasi website, crowdsourcing, codeigniter, extreme programming, lelang online, wedding organizer.

\section{PENDAHULUAN}

Media internet sudah menjadi media yang umum digunakan dalam bersosialisasi, periklanan, promosi, bertukar informasi bahkan melakukan bisnis online. Begitu pun dengan bisnis Wedding Organizer (WO) yang mulai menggunakan media internet sebagai media periklanan, promosi, serta memberikan informasi untuk mendapatkan pelanggannya. Selain itu, pada sisi pelanggan atau pengguna jasa WO, media internet digunakan untuk mencari informasi mengenai WO dan membandingkan reputasi WO untuk memilih WO.

Pada saat ini sudah terdapat beberapa website di Indonesia yang menggunakan konsep crowdsourcing untuk memudahkan pelanggan mencari WO. Namun, pada website yang telah dibangun sebelumnya, belum terdapat sistem yang dapat membantu pelanggan mencari dan membandingkan WO secara online dalam satu fungsi, sehingga pelanggan harus menemui WO satu per satu untuk memberikan penjelasan kebutuhan, negosiasi harga, membandingkan harga dan kualitas serta menentukan apakah WO dapat memenuhi kebutuhan pelanggan atau tidak.

Berdasarkan hasil kuesioner yang dilakukan terhadap 55 responden, menunjukkan bahwa $40 \%$ responden memprioritaskan harga dalam memilih WO, berarti responden mempertimbangkan penyesuaian harga yang ditawarkan oleh WO dengan anggaran yang dimiliki oleh responden. Sebanyak $38 \%$ dari responden, memprioritaskan banyaknya layanan yang ditawarkan oleh WO dan $12 \%$ responden mempertimbangkan pengalaman yang dimiliki WO. Hasil kuesioner ini menunjukkan bahwa harga adalah hal yang perlu dipertimbangkan dalam memilih WO. Sesuai dengan kelebihan dan cara kerja sistem lelang, sistem ini dapat menghasilkan harga yang optimal bagi penjual maupun pembeli. Hal tersebut menjadi potensi untuk membangun sistem dengan menggunakan metode lelang sebagai solusi terhadap kemudahan pelanggan dalam memilih WO yang sesuai dengan kebutuhan dan budget secara online.

Tujuan dari penelitian ini adalah merancang dan membangun aplikasi website yang dapat membantu pelanggan untuk mendapatkan informasi sampai proses memilih WO yang sesuai dengan keinginannya. Pada sisi WO, penelitian ini bertujuan untuk merancang dan membangun aplikasi website yang dapat membantu WO dalam memperkenalkan, mengiklankan dan mempromosikan produk dan jasanya kepada pelanggan. Selain itu, penelitian ini bertujuan untuk merancang dan membangun aplikasi website dengan menggunakan konsep crowdsourcing serta menerapkan sistem yang dapat membantu pelanggan untuk memilih WO dengan harga yang sesuai dengan keinginan pelanggan.

Manfaat dari penelitian ini adalah WO dapat meningkatkan keuntungan perusahaan, dapat memperkenalkan, mengiklankan dan mempromosikan produk/jasanya kepada pelanggan serta mendapatkan kemudahan dalam mendapatkan pelanggan. Akan tetapi, pada sisi pelanggan, pelanggan lebih mudah untuk mendapatkan informasi tentang WO dan memilih WO yang sesuai dengan harga dan keinginan. 


\section{Metodologi Penelitian}

\section{A. Extreme Programming}

Pada penelitian ini, digunakan Extreme Programming sebagai metode pengembangan software. Extreme Programming (XP) adalah disiplin pembangunan perangkat lunak berdasarkan nilai-nilai kesederhanaan, komunikasi, umpan balik, keberanian. Pada XP ini, setiap kontributor proyek adalah anggota "Whole Team", sebuah tim bisnis/pengembangan/pengujian tunggal yang menangani semua aspek pembangunan. Pusat pemikiran tim adalah "pelanggan", satu atau lebih bisnis yang bekerja sama dengan mereka setiap harinya [1].

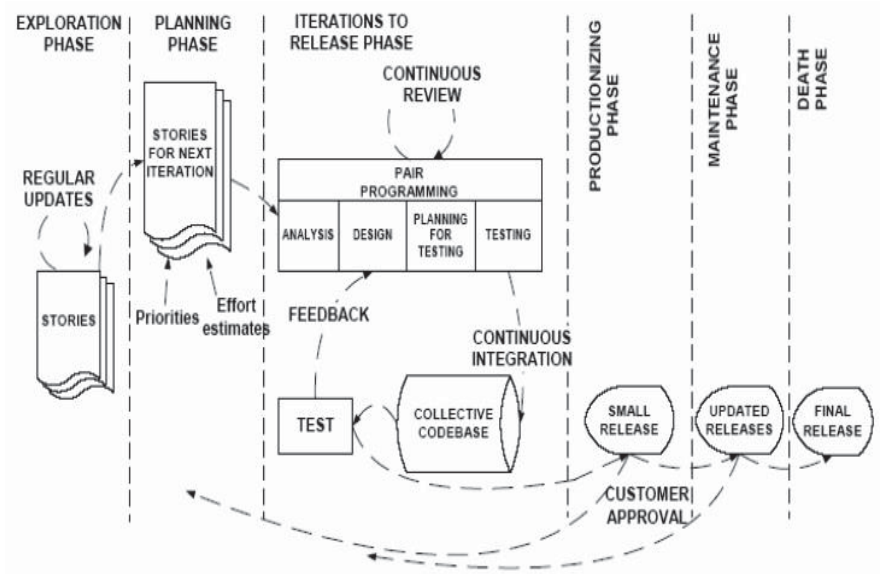

Gambar 1 Siklus Metode Pengembangan Software Extreme Programming [2]

XP menggunakan bentuk sederhana dari perencanaan dan menganalisis untuk memutuskan apa yang harus dilakukan selanjutnya dan bersifat responsif bila ada fitur yang akan dikembangkan pada dimasa yang akan datang sebagai perkembangan keinginan pengguna. XP digunakan saat mengembangkan aplikasi yang berpusat pada pengguna dan digunakan oleh tim kecil [1].

Siklus pengembangan software pada metode Extreme Programming (XP) mempunyai enam tahap (Gambar 1), yaitu sebagai berikut [2].

1. Fase eksplorasi, pada tahap ini, pengguna memberikan catatan atau dokumentasi mengenai kebutuhan yang diharapkan dapat terpenuhi pada software yang akan dikembangkan.

2. Fase perencanaan, pada tahap ini, didefinisikan prioritas kebutuhan pengguna pada software yang akan dikembangkan serta mengatur jadwal pengembangan sampai penyelesaian dan peluncuran software.

3. Fase iterasi menuju peluncuran, pada tahap ini, melakukan iterasi untuk membuat sistem dengan arsitektur dan menghasilkan progress.

4. Fase produksi, pada tahap ini, dilakukan pengujian dan pengecekan terhapdap performa software untuk selanjutnya dirilis.

5. Fase pemeliharaan, pada tahap ini, dilakukan pendokumentasian ide baru, kritik dan saran untuk selanjutnya digunakan dalam pengembangan software dengan versi baru (update software).

6. Fase akhir hidup, pada tahap ini, pengguna sudah tidak mempunyai pengalaman atau cerita terhadap software. Tahap ini terjadi ketika software tidak bisa memenuhi kebutuhan pengguna dan membutuhkan biaya yang besar jika dikembangkan.

\section{B. Model Konseptual}

Pada Gambar 2 menjelaskan model konseptual pada penelitian ini. Terdapat dua proses yang akan dibangun oleh peneliti. Proses ini didukung oleh latar belakang sebagai penjelasan masalah yang terjadi. Selain itu, dilandaskan oleh teori dasar yang digunakan oleh peneliti dalam membangun aplikasi website. Kedua proses tersebut diperkuat oleh kebutuhan pengguna dan fakta pada lingkungan. Dengan demikian, dilakukan survei untuk mendapatkan data kebutuhan pengguna.

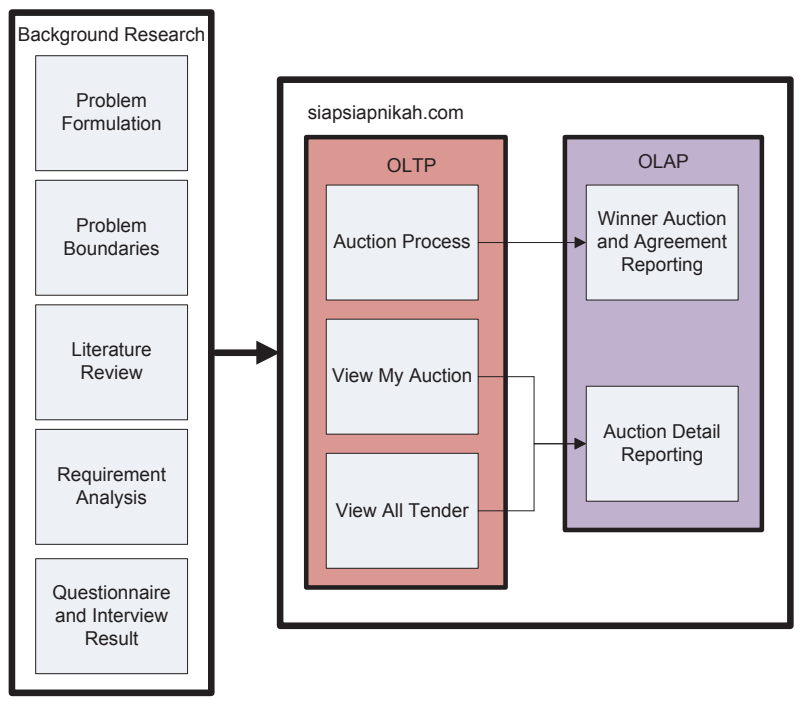

Gambar 2 Model Konseptual

Gambar 2 menggambarkan bahwa Online Transaction Process (OLTP) akan menghasilkan keluaran pada Online Analitycal Process (OLAP). Definisi OLTP adalah sebuah proses berorientasi sistem yang memproses transaksi langsung melalui komputer yang terkoneksi dengan jaringan, sedangkan OLAP adalah bagian dari Business intellegency untuk menyediakan dan mendukung laporan analisis. OLTP dan OLAP pada model konseptual dapat dilihat secara terperinci pada Tabel I.

TABEL I

OLTP DAN OLAP

\begin{tabular}{|l|l|l|l|}
\hline \multicolumn{1}{|c|}{ OLTP } & User (Actor) & \multicolumn{1}{|c|}{ OLAP } & User of the report \\
\hline $\begin{array}{l}\text { Auction } \\
\text { Process }\end{array}$ & Member, WO & $\begin{array}{l}\text { Winner Auction and } \\
\text { Agreement } \\
\text { Reporting }\end{array}$ & $\begin{array}{l}\text { Member, WO, } \\
\text { Administrator, } \\
\text { Moderator }\end{array}$ \\
\hline $\begin{array}{l}\text { View My } \\
\text { Tender }\end{array}$ & Member, WO & $\begin{array}{l}\text { Tender Detail } \\
\text { Reporting }\end{array}$ & $\begin{array}{l}\text { Member, WO, } \\
\text { Administrator, } \\
\text { Moderator }\end{array}$ \\
\cline { 1 - 2 } $\begin{array}{l}\text { View All } \\
\text { Tender }\end{array}$ & WO & & Moder \\
\hline
\end{tabular}




\section{HASIL DAN PEMBAHASAN}

\section{A. Wedding Organizer}

Wedding Organizer (WO) adalah bisnis yang menawarkan jasa pengorganisasian atau pengaturan aktivitas yang dilakukan dan dibutukan pada pesta pernikahan. Bisnis ini muncul karena adanya peluang untuk mengatasi tidak efisiennya waktu yang dimiliki oleh masyarakat perkotaan. WO biasanya menyediakan jasa undangan pernikahan, pembuatan baju pernikahan sampai souvenir pernikahan. Calon pengguna WO harus selektif dalam memilih WO yang andal dan dapat dipercaya. Agar dapat meraih target pasar, WO membutuhkan informasi tentang preferensi konsumen terhadap bisnis WO [3]

Wedding Organizer biasanya bekerja mulai dari prewedding, proses pernikahan sampai honeymoon trip. WO menangani apa yang diinginkan oleh pasangan mulai dari perencanaan pernikahan, check list, analisis anggaran, konsultasi pernikahan, upacara pernikahan, ide pernikahan yang unik, perawatan sebelum hari pernikahan, fotografi, musik, makanan, bunga dan dekorasi, kendaraan, menyewakan peralatan pernikahan dll. [4].

\section{B. Lelang Online}

Auction (lelang) adalah pasar dengan harga sebagai variabel dan didasarkan pada persaingan antar peserta yang akan membeli atau menjual produk dan jasa. Lelang adalah salah satu jenis dynamic pricing dengan harga produk bervariasi, tergantung pada karakteristik permintaan pelanggan dan situasi pasokan. Terdapat berbagai pasar harga dinamis, mulai dari tawar-menawar yang sederhana, barter dan negosiasi antara satu pembeli dan satu penjual, untuk lelang jauh lebih canggih karena mungkin ada ribuan penjual dan ribuan pembeli [5].

\section{Implementasi dari Konsep Crowdsourcing}

Kata crowdsourcing berawal dari kata outsourcing. Outsourcing adalah konsep yang mengalihkan pekerjaan dari suatu perusahaan, institusi atau organisasi ke perusahaan, institusi, organisasi atau individu lainnya. Sebagai contoh, kita mengetahui bahwa pada tahun 2000-an, banyak vendor-vendor besar, katakanlah Microsoft, SunMicrosistem, IBM, HewletPackard dan vendor lainnya, memberikan pekerjaan seperti menguji, mendeteksi celah suatu software pada perusahaan di India ataupun Cina. Dengan demikian perusahaan di India atau Cina mendapatkan keuntungan dan pekerjaan yang dilimpahkan kepadanya, dan vendor besar mendapatkan kemudahan dan penilaian objektif dari software yang dibuatnya [6].

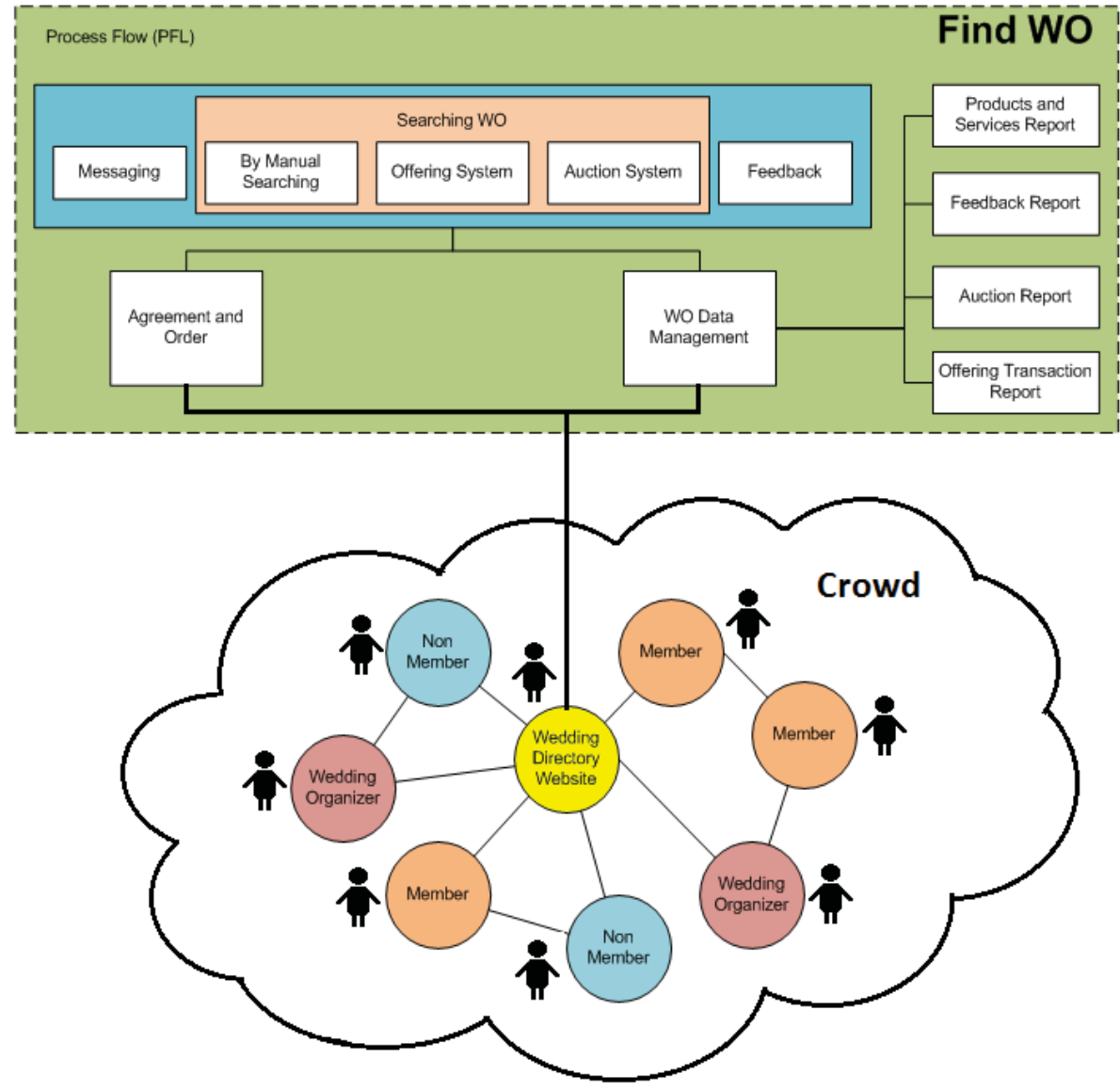

Gambar 3 Implementasi Konsep Crowdsourcing 
Crowdsourcing diartikan secara kata per kata mempunyai terjemahan bebas yakni Crowd yang berarti kerumunan orang, Sourcing (kata kerja dari Source) yang berarti sumber daya. Apabila digabungkan (masih dalam terjemahan bebas) akan berarti sebagai suatu sistem atau konsep dengan sumber daya berbasis kerumunan. Konsep umum crowdsourcing dimaksudkan adanya pelibatan yang tidak terbatas dan tanpa memandang latar belakang pendidikan, kewarganegaraan, agama, amatir atau professional, bagi setiap orang yang ingin memberikan kontribusinya atau solusinya atas suatu permasalahan yang dilemparkan oleh individu, perusahaan atau institusi, baik dibayar/royalti atau secara cuma-cuma [6].

Konsep crowd-creation adalah salah satu kategori crowdsoucing. Tujuan dari crowd-creation ini adalah untuk mendapatkan kepuasan pelanggan. Contoh dari konsep ini adalah YouTube, Wikipedia, 99designs [7]. Konsep crowdsourcing dengan menggunakan kategori crowd-creation sendiri akan membantu dan memudahkan pencari informasi dengan mendapatkan informasi tersebut dari banyak pihak. Pada website yang akan dibangun, terdapat banyak user yaitu lebih dari satu pelanggan dan lebih dari satu WO. Implementasi konsep crowdsourcing pada website ini akan membantu pelanggan untuk mencari dan memilih WO lebih cepat. Penggambaran implementasi crowdsourcing pada website yang dibangun dijelaskan pada Gambar 3.

\section{Konsep dan Fungsionalitas Aplikasi Modul Lelang}

Konsep modul lelang yang akan dibangun pada website adalah penerapan konsep crowdsourcing. Dalam hal ini, pelanggan mengajukan keinginan dan kebutuhan pernikahannya. Kemudian, WO dapat mengajukan harga sesuai dengan kebutuhan pelanggan. Pelanggan dapat memilih WO berdasarkan reputasi, layanan dan harga ajuan WO. Dengan demikian pelanggan dapat mempertimbangkan harga, layanan dan pengalaman WO dalam memilih WO yang sesuai dengan keinginan dan budget pelanggan secara online dan tidak perlu menemui WO satu per satu.

Aplikasi web siapsiapnikah.com dibangun dengan menggunakan konsep crowdsourcing, aplikasi web menyediakan banyak informasi yang didapatkan dari lebih dari satu wedding organizer. Informasi ini ditujukan kepada pelanggan yang ingin mencari informasi dan akan menggunakan jasa WO. Aplikasi web ini diharapkan dapat membantu pelanggan dalam memilih WO yang sesuai dengan kebutuhan dan budget. Berikut ini adalah fungsionalitas yang dibangun dalam sistem lelang pada aplikasi website siapsiapnikah.com.

1. Buka Tender Baru

Berdasarkan metode lelang, tender adalah objek untuk menawarkan produk, servis atau kebutuhan yang akan ditawakan pada lelang. Fungsi ini digunakan oleh member untuk mengajukan kebutuhan pernikahan mereka. Formulir untuk membuka tender ini terdiri dari judul lelang, tanggal pernikahan, tanggal tutup lelang, lokasi pernikahan, jumlah undangan, dan detail setiap kategori produk pernikahan.

\section{Pengajuan Harga}

Fungsi ini digunakan oleh WO setelah member mengajukan kebutuhan pernikahannya. WO dapat mengajukan harga sesuai dan berdasarkan pada kebutuhan pernikahan member yang sudah diajukan. Satu tender dapat terdiri atas banyak harga dari banyak WO.

3. Menutup Tender Tanpa Memilih WO

Fungsi ini digunakan oleh member untuk menutup tender tanpa pemenang tender. Hal ini dapat disebabkan karena tidak ada WO atau harga yang cocok dengan keinginan dan budget member ataupun tidak ada WO yang mengajukan harga pada tender tersebut.

4. Menutup Tender Dengan Memilih WO

Fungsi ini digunakan ole member untuk menutup dan memilih WO. Member mendapatkan tender dan memilih WO dapat disebabkan karena mereka mendapatkan WO atau harga yang cocok dengan keinginan dan budget-nya. Sebelum member memilih WO, member dapat melihat terlebih dahulu profil WO untuk membandingkan pelayanan dan reputasi WO. 5. Daftar Permintaan

Fungsi ini deigunakan WO untuk menyetujui atau membatalkan permintaan untuk menjadi pemenang dan memberikan pelayanan sesuai detail tender. WO dapat melihat terlebih dahulu info mengenai pemilik tender.

\section{E. Hasil Aplikasi}

Berikut beberapa hasil User Interface dari aplikasi website yang dibangun:

Pada Gambar 4 ditampilkan halaman login untuk semua user. Untuk dapat menggunakan sistem lelang, pengguna diharuskan menjadi member dan melakukan login terlebih dahulu. Tombol submit akan mengecek kesamaan username, password dan tipe user dengan data yang sudah ada di database. Pengecekan ini akan menentukan user akan ditujukan ke halaman mana.

Halaman utama member dapat dilihat pada Gambar 5. Setelah login berhasil maka member akan ditujukan ke halaman ini. Pada halaman utama ditampilkan penghubung menuju sistem lelang. Sistem lelang termasuk kedalam fitur pencarian dan pemilihan WO seperti yang digambarkan pada Gambar 6 . Maka dari itu, penghubung ini digabung bersama sistem pencarian lainnya. Selain itu, pada penghubung ini terdapat langkah-langkah penggunaan sistem lelang, sehingga pengguna dapat mengggunakan sistem ini dengan mudah.

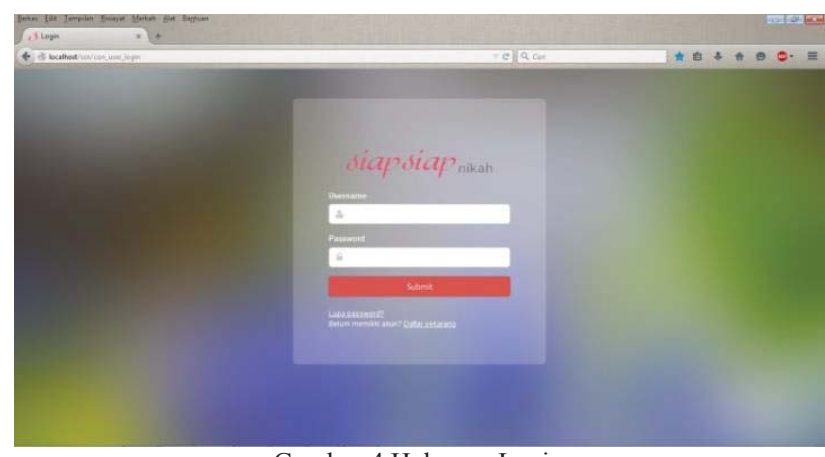

Gambar 4 Halaman Login 


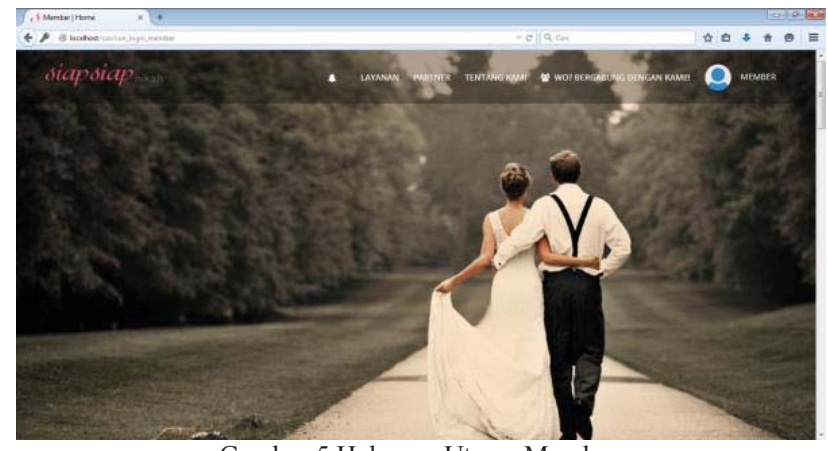

Gambar 5 Halaman Utama Member

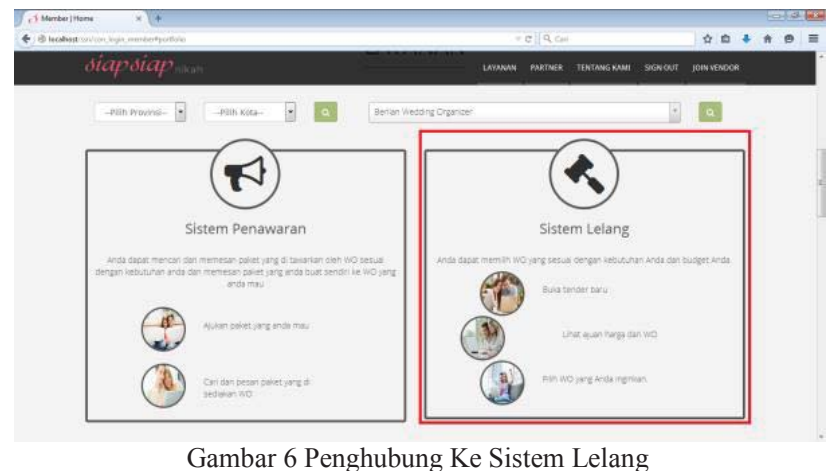

Gambar 6 Penghubung Ke Sistem Lelang

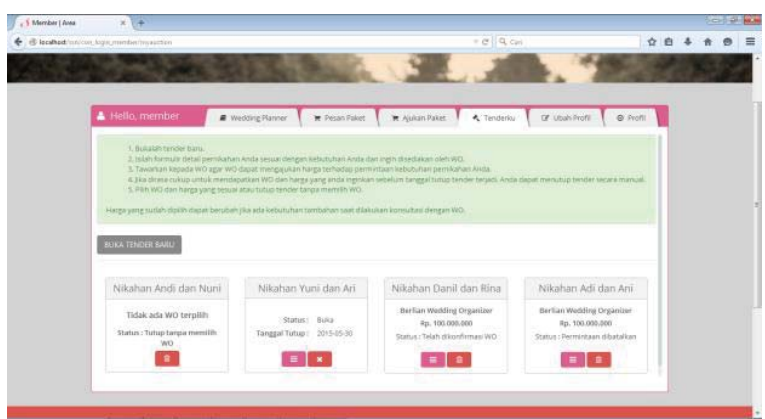

Gambar 7 Tampilan Halaman Tenderku

Halaman tenderku menampilkan tender yang telah dibuka oleh member dan terdapat tombol untuk membuka tender baru. Dapat dilihat pada Gambar 7, halaman ini memberikan informasi langkah-langkah menggunakan sistem lelang dan informasi mengenai harga yang akan dipilih member ketika menutup tender. Di setiap tender terdapat status, dan tomboltombol yang berfungsi sesuai dengan status. Terdapat tiga tombol yang akan mucul sesua dengan status tender yaitu, uraian tender, tutup tender dan hapus tender.

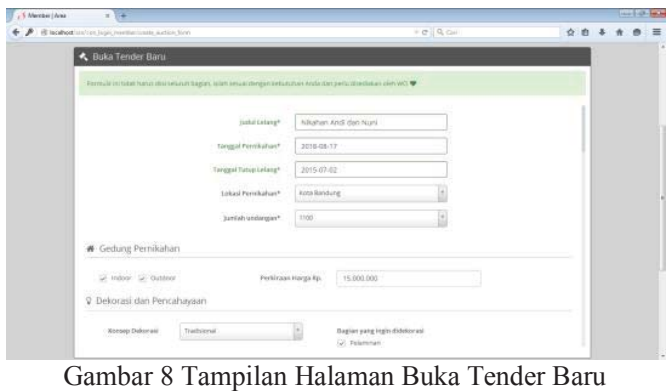

Gambar 8 Tampilan Halaman Buka Tender Baru
Untuk membuka tender baru, member tidak diharuskan mengisi semua bagian dari formulir. Seperti yang terlihat pada Gambar 8, judul lelang, tanggal pernikahan, tanggal tutup lelang, lokasi pernikahan, dan jumlah undangan wajib diisi. Namun, untuk pengisian detail kategori produk dan jasa yang disediakan oleh WO, member disarankan untuk mengisi sesuai dengan kebutuhan pernikahannya. Setiap kategori mempunyai detail yang berbeda-beda dan memiliki isian budget yang berbeda pula. Dengan demikian, WO dapat mengatahui keinginan dan kebutuhan member secara detail serta budget yang disediakan pada setiap kategori produk dan jasa pernikahan.
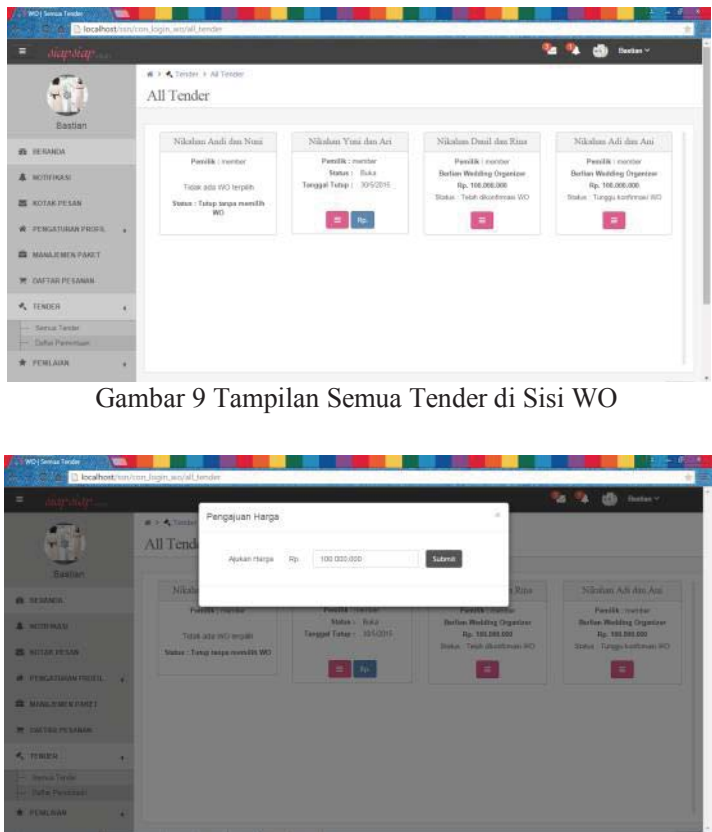

Gambar 10 Tampilan Pengajuan Harga di Sisi WO

Gambar 9 adalah tampilan semua tender disisi WO. Seperti halaman tenderku disisi member, tender-tender yang ada disisi WO pun mempunyai aksi-aksi sesuai dengan status tender. Jika status tender adalah buka, maka WO dapat mengajukan harga pada tender tersebut. Formulir pengajuan harga dapat dilihat pada Gambar 10.

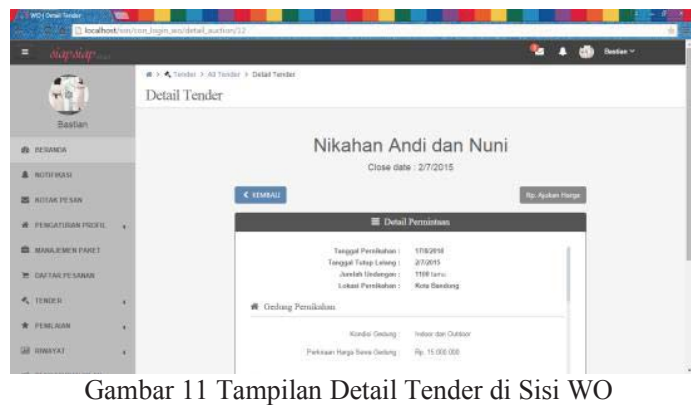

Pada Gambar 11 dan Gambar 12, digambarkan tampilan detail tender disisi member dan disisi WO. Terlihat bahwa ada perbedaan dari keduanya, yaitu daftar harga hanya ditampilkan 
disisi member. Hal ini ditujukan agar WO tidak dapat mengecilkan harga yang bertujuan agar WO dapat dipilih oleh member karna mengajukan harga terkecil. Daftar ajuan harga pada sisi member juga bertujuan agar member dapat melihat profil WO terlebih dahulu sebelum menutup tender dan memilih WO.
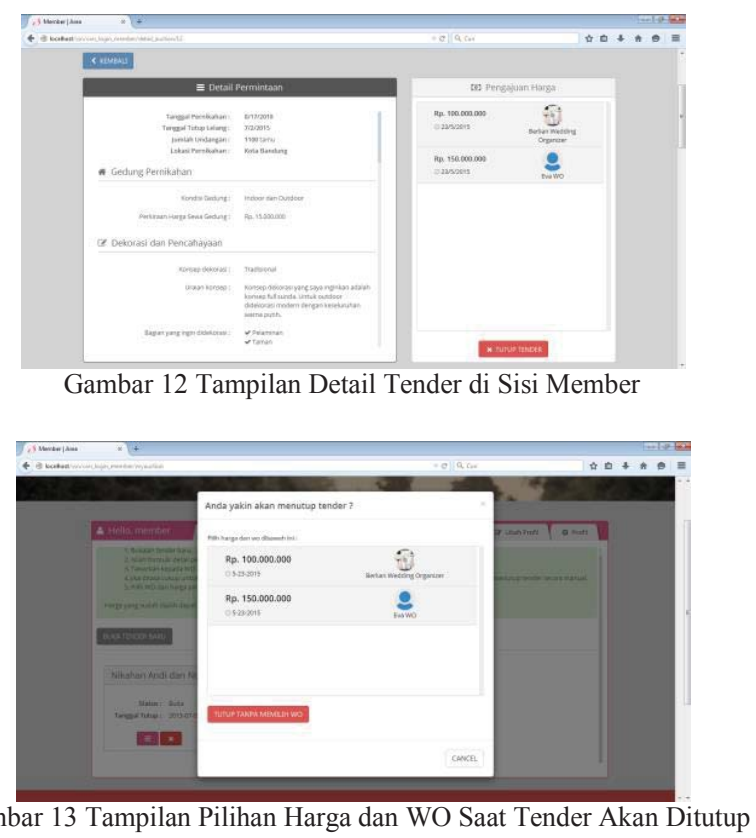

Gambar 13 menampilkan tampilan saat member akan menutup tender. Pada tampilan ini terdapat dua pilihan bagi member, yaitu menutup tender dengan memilih WO atau menutup tender tanpa memilih WO. Jika member akan menutup tender dan memilih WO maka tampilan akan seperti pada Gambar 14, kemudian jika member akan menutup tender tanpa memilih WO maka tampilan akan seperti pada Gambar 15.

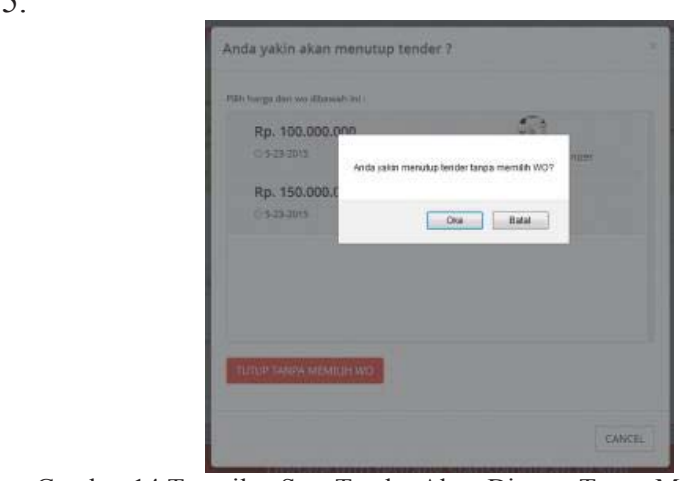

Gambar 14 Tampilan Saat Tender Akan Ditutup Tanpa Memilih WO

Dari tampilan pada Gambar 14 dan Gambar 15, apabila member menutup tender dan memilih WO, maka WO yang dipilih akan menerima permintaan. Gambar 16 menggambarkan tampilan daftar permintaan disisi WO. Daftar permintaan ini dikhususkan hanya untuk permintaan member hasil dari lelang. Pada tampilan daftar permintaan terdapat aksi terima atau tolak permintaan. Selain itu, terdapat aksi untuk menghapus, melihat detail tender dan melihat info pemilih.
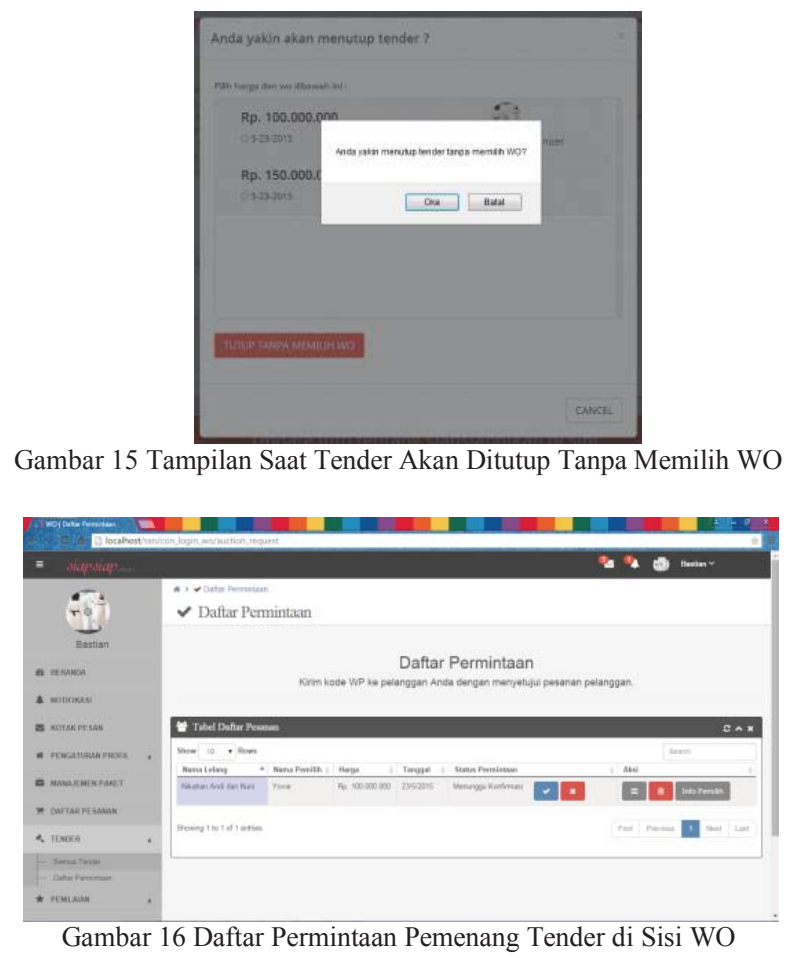

F. Pengujian Aplikasi

Pada penelitian ini, peneliti melakukan pengujian aplikasi untuk mengetahui apakah aplikasi bekerja dengan baik atau tidak. Pengujian yang dilakukan menggunakan metode Unit Testing, Usability Testing dengan skala SERVQUAL untuk menghitung kualitas layanan.

1. Unit Testing

Unit testing adalah pengujian aplikasi pertama dan level paling bawah pada level pengujian aplikasi. Pengujian ini dilakukan oleh programmer untuk menguji suatu modul. Pada pengujian ini terdapat dua tipe pengujian yaitu Buddy Testing dan Automated Unit Testing. Buddy testing adalah pengujian yang dilakukan dengan pendekatan developer team. Pada pengujian ini tugas pengujian diberikan kepada rekan developer pada suatu tim, sedangkan Automated unit testing adalah pengujian yang dilakukan di dalam IDE dari programmers [8].

Pada pengujian unit, peneliti menggunakan Buddy Testing, tugas pengujian diberikan kepada rekan satu tim dalam pengembangan aplikasi. Pada pengujian ini, peneliti memberikan dua jenis skenario pengujian yaitu test-to-pass dan test-to-fail. Test-to-pass adalah pengujian yang dilakukan oleh peneliti dengan memasukkan data yang benar sehingga keluaran yang diharapkan adalah berhasil. Sedangkan test-tofail adalah pengujian yang dilakukan oleh peneliti dengan memasukkan data yang salah sehingga keluaran yang diharapkan adalah tidak berhasil karena data yang dimasukkan salah.

Selain itu, pengujian akan dilakukan pada dua media aplikasi browser yaitu Mozilla Firefox dan Google Chrome. Peneliti memberikan 17 tugas terhadap modul lelang pada siapsiapnikah.com. Tugas-tugas ini harus dilakukan terhadap kedua browser dan dipenuhi secara satu persatu atau 
keseluruhan. Pada Tabel II diuraikan tugas-tugas yang harus dipenuhi beserta jenis scenario yang dilakukan, apakah test-topass atau test-to-fail pada setiap tugas. Sedangkan, pada Tabel III diuraikan mengenai hasil dari pengujian. Hasil pengujian dijelaskan berdasarkan aplikasi browser yang digunakan untuk pengujian.

TABEL II

RENCANA PENGUJIAN

\begin{tabular}{|c|c|c|c|}
\hline Kode & \multicolumn{2}{|c|}{ Uraikan Aktivitas } & Pengujian \\
\hline A1-01 & \multirow{2}{*}{\multicolumn{2}{|c|}{ Membuka tender baru }} & Test to pass \\
\hline A1-02 & & & Test to fail \\
\hline A2-01 & \multicolumn{2}{|c|}{$\begin{array}{l}\text { Membuka detail tender yang dibuka (sisi } \\
\text { member) }\end{array}$} & Test to pass \\
\hline A3-01 & \multicolumn{2}{|c|}{$\begin{array}{l}\text { Membuka detail tender yang ditutup (sisi } \\
\text { member) }\end{array}$} & Test to pass \\
\hline A4-01 & \multirow{2}{*}{$\begin{array}{l}\text { Membuka detail tender } \\
\text { yang dibuka (sisi WO) }\end{array}$} & $\begin{array}{l}\text { Melalui halaman } \\
\text { beranda }\end{array}$ & Test to pass \\
\hline A5-01 & & $\begin{array}{l}\text { Melalui halaman } \\
\text { semua tender }\end{array}$ & Test to pass \\
\hline A6-01 & \multirow{2}{*}{$\begin{array}{l}\text { Membuka detail tender } \\
\text { yang ditutup (sisi WO) }\end{array}$} & $\begin{array}{l}\text { Melalui halaman } \\
\text { beranda }\end{array}$ & Test to pass \\
\hline A7-01 & & $\begin{array}{l}\text { Melalui halaman } \\
\text { semua tender }\end{array}$ & Test to pass \\
\hline A8-01 & \multirow{4}{*}{$\begin{array}{l}\text { Mengaj-ukan } \\
\text { Harga }\end{array}$} & \multirow{2}{*}{$\begin{array}{l}\text { Melalui halaman } \\
\text { beranda }\end{array}$} & Test to pass \\
\hline A8-02 & & & Test to fail \\
\hline A9-01 & & \multirow{2}{*}{$\begin{array}{l}\text { Melalui halaman } \\
\text { semua tender }\end{array}$} & Test to pass \\
\hline A9-02 & & & Test to fail \\
\hline A10-01 & \multicolumn{2}{|c|}{ Menutup tender dan memilih WO } & Test to pass \\
\hline A11-01 & \multicolumn{2}{|c|}{ Menutup tender tanpa memilih WO } & Test to pass \\
\hline A12-01 & \multicolumn{2}{|c|}{ Menghapus tender } & Test to pass \\
\hline A13-01 & \multicolumn{2}{|c|}{ Menerima permintaan (sisi WO) } & Test to pass \\
\hline A14-01 & \multicolumn{2}{|c|}{ Membatalkan permintaan (sisi WO) } & Test to pass \\
\hline
\end{tabular}

TABEL III

HASIL PENGUJIAN

\begin{tabular}{|l|c|}
\hline \multicolumn{1}{|c|}{ Browser Apps } & Hasil (berhasil/total) \\
\hline Mozilla Firefox & $17 / 17(100 \%)$ \\
\hline Google Chrome & $17 / 17(100 \%)$ \\
\hline
\end{tabular}

\section{System Testing}

System testing adalah pengujian yang dilakukan oleh calon pengguna. Pengujian ini dilakukan setelah sistem dibangun. Pengujian ini memiliki dua teknik yaitu structural techniques dan functional techniques [8]. Untuk menguji aplikasi menggunakan system testing, peneliti memilih functional techniques untuk mengetahui apakah aplikasi dapat digunakan dengan baik atau tidak.

Pengujian ini dilakukan kepada tujuh pelanggan dan dua WO. Terdapat perbedaan skenario diantara penguji tersebut. Pelanggan akan diarahkan untuk memenuhi tugas pada member area, sedangkan WO akan diarahkan untuk memenuhi tugas pada area WO. Tampilan dan fungsi yang dijalankan oleh kedua jenis penguji pun berbeda.

Pada Tabel V, dijelaskan mengenai hasil dari pengujian sistem. Semua tugas dapat dilakukan dengan baik oleh penguji. Pada hasil pengujian disisi pelanggan terdapat error pada tugas nomor 4. Hal ini disebabkan karena variabel yang dikirim ke fungsi tidak memenuhi syarat URL, sehingga, satu penguji mengalami kegagalan dalam memenuhi tugas nomor 4 dan menemukan bug yang sebaiknya diperbaiki oleh developer.

TABEL IV

HASIL UMPAN BALIK DARI PENGUJI MENGGUNAKAN SKALA SERVQUAL

\begin{tabular}{|c|c|c|c|c|c|}
\hline No. & Skala & Pertanyaan & SS & $\mathrm{S}$ & ST \\
\hline 1. & \multirow[b]{2}{*}{ Web Design } & Apakah navigasi, menu dan fungsi pada website ini mudah digunakan dan mudah dimengerti? & $33 \%$ & $67 \%$ & $0 \%$ \\
\hline 2. & & $\begin{array}{l}\text { Apakah desain pada website ini seperti penempatan ikon, gambar dan warna membuat Anda } \\
\text { nyaman menggunakan website ini? }\end{array}$ & $44 \%$ & $56 \%$ & $0 \%$ \\
\hline 3. & \multirow[t]{2}{*}{ Reliability } & $\begin{array}{l}\text { Apakah website ini mengakomodasi pengguna untuk mencari wedding organizer dan harga yang } \\
\text { sesuai dengan keinginan pengguna? }\end{array}$ & $57 \%$ & $43 \%$ & $0 \%$ \\
\hline 4. & & Apakah website ini mengakomodasi pengguna untuk menerima pesanan diluar paket? & $50 \%$ & $50 \%$ & $0 \%$ \\
\hline 5. & \multirow[b]{2}{*}{ Responsiveness } & Apakah website ini menyediakan mekanisame untuk mendukung aktifitas pengguna? & $22 \%$ & $78 \%$ & $0 \%$ \\
\hline 6. & & $\begin{array}{l}\text { Apakah website ini menyediakan mekanisme untuk mendukung komunikasi antarapengguna } \\
\text { dengan pemilik website? }\end{array}$ & $56 \%$ & $33 \%$ & $11 \%$ \\
\hline 7. & \multirow[t]{2}{*}{ Security } & $\begin{array}{l}\text { Apakah website ini menyediakan mekanisme untuk meyakinkan pengguna bahwa data dapat } \\
\text { terimpan dengan aman? }\end{array}$ & $67 \%$ & $22 \%$ & $11 \%$ \\
\hline 8. & & Apakah website ini menyediakan mekanisme untuk melindungi aktivitas dan data pengguna? & $67 \%$ & $33 \%$ & $0 \%$ \\
\hline 9. & \multirow{4}{*}{ Fulfillment } & Apakah website ini sudah mencapai tujuan utamanya? & $44 \%$ & $56 \%$ & $0 \%$ \\
\hline 10. & & $\begin{array}{l}\text { Apakah website ini dapat membantu untuk mencari WO dan harga yang sesuai dengan keinginan } \\
\text { pengguna? }\end{array}$ & $71 \%$ & $29 \%$ & $0 \%$ \\
\hline 11. & & $\begin{array}{l}\text { Apakah website ini dapat membanti untuk mengiklankan dan mempromosikan produk dan } \\
\text { jasanya? }\end{array}$ & $100 \%$ & $0 \%$ & $0 \%$ \\
\hline 12. & & Apakah website ini dapat membantu untuk mendapatkan pelanggan lebih mudah? & $50 \%$ & $50 \%$ & $0 \%$ \\
\hline 13. & Personalization & Apakah website ini memberikan nilai tambah pada pelanggan? & $57 \%$ & $43 \%$ & $0 \%$ \\
\hline 14. & \multirow{3}{*}{ Information } & Apakah website ini menyediakan informasi produk/jasa terbaru? & $43 \%$ & $57 \%$ & $0 \%$ \\
\hline 15. & & Apakah website ini menyediakan informasi yang mudah dimengerti? & $43 \%$ & $57 \%$ & $0 \%$ \\
\hline 16. & & $\begin{array}{l}\text { Apakah website ini menyediakan fasilitas untuk membuat informasi terbaru mengenai produk } \\
\text { dan jasa dari WO? }\end{array}$ & $50 \%$ & $50 \%$ & $0 \%$ \\
\hline 17. & \multirow[t]{2}{*}{ Empathy } & $\begin{array}{l}\text { Apakah website ini menyediakan sistem untuk membuat komunikasi yang bagus antar } \\
\text { pengguna? }\end{array}$ & $22 \%$ & $67 \%$ & $11 \%$ \\
\hline 18. & & Apakah website ini memiliki informasi mengenai kontak yang dapat dihubungi? & $78 \%$ & $22 \%$ & $0 \%$ \\
\hline
\end{tabular}

Keterangan: $\mathrm{SS}=$ Sangat Setuju, $\mathrm{S}=$ Setuju, $\mathrm{TS}=$ Tidak Setuju 
TABEL V

HASIL SYSTEM TESTING

\begin{tabular}{|c|l|l|}
\hline \multicolumn{3}{|c|}{ Sisi Member } \\
\hline No. & \multicolumn{1}{|c|}{ Tugas } & \multicolumn{1}{|c|}{ Hasil } \\
\hline 1. & Membuka tender baru & $7 / 7(100 \%)$ \\
\hline 2. & Membuka detail tender & $7 / 7(100 \%)$ \\
\hline 3. & Menutup tender dan memilih WO & $6 / 7(85.71 \%)$ \\
\hline 4. & Menutup tender tanpa memilih WO & $7 / 7(100 \%)$ \\
\hline 5. & Menghapus tender & $7 / 7(100 \%)$ \\
\hline \multicolumn{3}{|c|}{ Sisi WO } \\
\hline 1. & Buka halaman semua tender & $2 / 2(100 \%)$ \\
\hline 2. & Buka detail salah satu tender & $2 / 2(100 \%)$ \\
\hline 3. & Ajukan harga ke salah satu tender. & $2 / 2(100 \%)$ \\
\hline 4. & Buka halaman daftar permintaan tender. & $2 / 2(100 \%)$ \\
\hline 5. & Buka info pemilih & $2 / 2(100 \%)$ \\
\hline 6. & Buka detail tender & $2 / 2(100 \%)$ \\
\hline 7. & Memnerima permintaan & $2 / 2(100 \%)$ \\
\hline 8. & Membatalkan permintaan & $2 / 2(100 \%)$ \\
\hline 9. & Menghapus permintaan & $2 / 2(100 \%)$ \\
\hline
\end{tabular}

\section{Acceptance Testing}

Acceptance testing adalah pengujian yang dilakukan setelah system testing. Pengujian ini dilakukan oleh pengguna untuk mengetahui apakah aplikasi sudah memenuhi kebutuhan pengguna atau tidak dan apakah aplikasi dapat menghasilkan kepuasan terhadap pengguna atau tidak [8].

Pada pengujian ini, peneliti menggunakan skala SERVQUAL sebagai dimensi untuk menghitung kualitas layanan dari aplikasi website yang dibangun. Skala SERVQUAL sudah digunakan untuk menghitung kualitas layanan pada berbagai industri, dan beberapa penelitian menggunakan model SERVQUAL untuk menghitung pada konteks $e$-service pada beberapa barang [9].

Pada Tabel IV, diuraikan pertanyaan-pertanyaan yang diajukan dan diklasifikasikan berdasarkan skala SERVQUAL. Selain itu, dijelaskan juga mengenai persentase jawaban dari penguji sebagai hasil pengujian. Pertanyaan tersebut diajukan kepada tujuh pelanggan dan dua wedding organizer. Untuk setiap jenis penguji diberikan pertanyaan yang berbeda sesuai dengan fungsi aplikasi yang dicoba.

\section{KESIMPULAN DAN SARAN}

Aplikasi website siapsiapnikah.com adalah aplikasi wedding directory website yang bertujuan untuk membantu pelanggan dalam menemukan produk atau jasa pernikahan pada Wedding Organizer yang sesuai dengan kebutuhannya. Pada aplikasi website ini dibangun sebuah sistem yang dapat membantu pelanggan untuk mencari dan mendapatkan WO yang sesuai dengan kebutuhan dan budget pelanggan. Selain itu website ini menyediakan informasi mengenai $\mathrm{WO}$ dan reputasi WO berdasarkan rating dari pengguna.

Sistem lelang adalah sistem pemilihan WO dengan menggunakan metode lelang. Pada sistem ini pelanggan memberikan detail permintaan kebutuhan pernikahannya, untuk kemudian WO dapat mengajukan harga terhadap permintaannya. Setelah dirasa cukup mendapatkan pilihan WO, pelanggan dapat memilih WO dengan pertimbangannya saat memilih WO. Sistem ini memberikan informasi mengenai harga yang diajukan dan reputasi WO sebagai hal yang perlu dipertimbangkan pelanggan saat memilih WO. Harga dapat berubah apabila ada tambahan kebutuhan saat dilakukannya konsultasi dengan WO.

Manfaat atau dampak positif yang dapat dirasakan dari pengembangan sistem ini adalah pelanggan dapat menghemat waktu dan tenaga untuk mencari WO yang sesuai dengan budget dan konsep mereka. Pelanggan tidak perlu menghubungi atau mendatangi langsung kantor WO untuk membandingkan harga dan kualitas WO. Sistem ini juga dapat menyortir WO yang dapat memenuhi kebutuhan pelanggan dari banyak WO yang bergabung pada website, sehingga pelanggan tidak perlu menghubungi semua WO yang bergabung di website maupun di seluruh Indonesia untuk melakukan perbandingan. Kesimpulannya, pelanggan dapat menghubungi hanya beberapa WO yang sudah mengajukan harga pada lelang dan sesuai dengan kebutuhannya.

Selain dampak positif yang ditimbulkan dalam pengembangan sistem ini, terdapat dampak negatif atau risiko buruk di masa yang akan datang. Dampak tersebut adalah akan berkurangnya ketertarikan WO untuk mengikuti lelang yang dibuka oleh calon pengantin. Hal ini dapat disebabkan oleh ketidakberhasilan WO untuk mendapatkan pelanggan dengan mengikuti sistem yang dibangun. Sehingga, ada kemungkinan WO dapat berpindah menggunakan sistem lain atau kembali ke cara konvensional.

Untuk pengembangan lebih lanjut, aplikasi ini dapat ditambahkan fitur komentar pada setiap tender untuk menanyakan lebih detail dari sisi WO kepada pelanggan. Dengan demikian WO dapat mendapatkan informasi lebih dari detail yang diberikan oleh pelanggan dan dapat memberikan harga lebih akurat. Selain itu, desain website sebaiknya lebih bagus untuk membuat sistem lebih menarik dan memperjelas fungsi navigasi dan menu yang ada.

\section{DAFTAR PUSTAKA}

[1]. Lindstrom, Lowell \& Jeffries, Ron (2004). Extreme Programming and Agile Software Development Methodologies. Auerbach Publication Inc.

[2]. Awad, M. A. (2005). A Comparison between Agile and Traditional Software Development Methodologies. The University of Western Australia.

[3]. Arum, R. E. (n.d). Lingkungan Bisnis "Wedding Organizer".

[4]. Pongsiri, Kingkan (2014). Wedding in Thailand: Traditional and Business. International Journal of Social, Management, Economics and Business Engineering, 8, $2792-2796$

[5]. Laudon, Kenneth C. \& Traver, Carol Guercio (2010). ECommerce Business. Technology. Society Sixth Edition. United State of America: Pearson Education, Inc.

[6]. Andriansyah, M \& T. O. (n.d.). (2007). Crowdsourcing: Konsep Sumber Daya Kerumunan dalam Abad Partisipasi Komunitas Internet. 1-6.

[7]. Rahmawan, B., Prasetyo, Y.A., \& Wiyogo, M. (2013). Membangun portal web crowdsourcing health treatment dengan menggunakan metode iterative incremental dan 
metode pencarian vector space model. Bandung: IT Telkom.

[8]. Khan, M.E. (2011). Different Software Testing Levels for Detecting Errors. International Journal of Software Engineering (IJSE), Volume (2), Issue (4), pp. 70-80.

[9]. Li Hongxiu \& Soumi Reima (2009). A Proposed Scale for Measuring E-service Quality. Information Sistem Science Institute, Turku School of Economics, Finland. 